\title{
Cross Sectional: Dukungan Sosial dan Resiliensi Perawat
}

\author{
Okti Rahayu Asih', Rahmi Fahmy ${ }^{2}$, Dwi Novrianda ${ }^{3}$, Henny Lucida ${ }^{4}$, Vetty Priscilla ${ }^{5}$, Zifriyanthi Minanda Putri ${ }^{6}$ \\ Fakultas Keperawatan Universitas Andalas, Limau Manis Padang ${ }^{1}$ \\ Fakultas Manajemen Universitas Andalas, Limau Manis Padang ${ }^{2}$ \\ Fakultas Keperawatan Universitas Andalas, Limau Manis Padang ${ }^{3}$ \\ Fakultas Farmasi Universitas Andalas, Limau Manis Padang ${ }^{4}$ \\ Fakultas Keperawatan Universitas Andalas, Limau Manis Padang ${ }^{5}$ \\ Fakultas Keperawatan Universitas Andalas Padang ${ }^{6}$ \\ e-mail: oktirasih@yahoo.com
}

\begin{abstract}
Resilience is an essential element to be built in the nursing profession in order to overcome challenges and difficulties in the workplace. Relationship and effective support that comes from family, friends and peers are factors that influence resilience. To examine the relationship between social support and nurse resilience. This research applied a quantitative design with cross sectional approach. The samples were taken by proportional random sampling and 110 nurses were chosen as the samples. The instruments in this study were CD-RISC 10 and MSPSS with modified. There is a relationship between social support and nurse resilience. Suggestion: Hospital management may design an innovative and creative programs to increase nurses' perceived social support such as family gathering programs, family hospital tour programs and mentoring as an effort to increase their resilience
\end{abstract}

Keywords: Nurse; Social support; resilience

\section{PENDAHULUAN}

Perawat merupakan profesi yang banyak mengalami tekanan dan situasi traumatis baik secara langsung maupun tidak langsung (Cam and Buyukbayram, 2015). Beberapa tantangan yang dihadapi perawat yaitu intimidasi, pelecehan dan kekerasan, perubahan organisasi, masalah kesehatan dan keselamatan kerja (Cameron and Brownie, 2010). Selain itu, beban kerja yang berlebihan, konflik peran, serta konflik kerja dengan tenaga kesehatan lain, rekan sejawat maupun atasan merupakan permasalah tersendiri yang dialami oleh perawat (Jackson, Firtko, \& Edenborough, 2007, McAllister, Lowe, 2011, Yilmaz, 2017).

Hal ini dapat menimbulkan kerugian baik bagi perawat secara individu maupun bagi pasien (Wang et al., 2017). Banyaknya permasalahan, tantangan dan kesulitan di tempat kerja dapat menyebabkan stress dan kejenuhan dalam bekerja (burnout) (Jackson, Firtko, \& Edenborough, 2007, McAllister, Lowe, 2011, Yilmaz, 2017). Stres kerja dan burnout dapat berefek pada menurunkan kualitas keperawatan dan menurunkan kepuasan pasien (Rogers et al., 2004, Poghosyan et al., 2010, Nantsupawat et al., 2016).

Resiliensi merupakan hal yang dapat membantu untuk mengurangi berbagai efek negatif bagi para professional yang bekerja dalam situasi kerja yang penuh tekanan (Mccann et al., 2013). Resiliensi adalah kemampuan individu untuk bangkit kembali dalam mengatasi situasi sulit (Rutter, 2008). Resiliensi di tempat kerja merupakan suatu sarana untuk memfasilitasi seseorang untuk beradaptasi terhadap lingkungan yang penuh dengan tekanan, seperti pada profesi keperawatan (Gillespie, Chaboyer and Wallis, 2009).

Dukungan sosial adalah proses hubungan sosial dan interaksi yang meliputi emosional, kognitif dan perilaku yang membantu seseorang untuk beradaptasi dan mengatasi situasi (Sarason and Duck, 2001). Menurut Xu \& Burleson (2001) dukungan sosial adalah bantuan dari orang lain untuk mengatasi perubahan dalam hidup serta mengatasi tuntutan masalah.
Dukungan sosial biasa diberikan pada saat interaksi biasa dan pada saat seseorang membutuhkan dukungan saat menghadapi kesulitan dan tantangan (Jooyoung, 2012).

Menurut Zimet (1988) dukungan sosial berasal dari keluarga, teman dan orang lain yang berarti (significant others). Adapun yang termasuk significant others yaitu kelompok sosial, yang dalam hal ini termasuk teman-teman sejawat (Zimet, 1988, Wang et al, .2017). Hal ini sejalan dengan Narayanan \& Onn (2016) dan Wang et al (2017) yang menyatakan dukungan sosial bisa berasal dari keluarga, teman dan teman sekerja.

Dukungan sosial dengan keluarga, teman, dan rekan sejawat, dapat membantu perawat mengatasi situasi yang ada di tempat kerja. Adanya usaha agar perawat dihubungkan kembali dengan orang-orang yang memiliki hubungan dekat dengan perawat akan memungkinkan perawat untuk kembali fokus dan berkontribusi pada kemampuan perawat menghadapi situasi sulit saat bekerja. Dalam hal ini keseimbangan pekerjaan-hidup merupakan hal penting bagi perawat untuk meningkatkan resiliensi (Ablett and Jones, 2006).

Dukungan secara emosional membuat seseorang merasakan adanya perhatian yang membuat mereka merasa lebih nyaman saat menghadapi kesulitan (Xu and Burleson, 2001). Melalui adanya hubungan yang berarti serta dukungan sosial sangat penting yang menandakan seseorang diterima (Tusaie and Dyer, 2004), ada perasaan memiliki (Sippel et al., 2015) serta menurunkan stress (Ren, 2018) dan emosi negatif yang pada akhirnya meningkatkan resiliensi (Narayanan and Onn, 2016).

Beberapa penelitian menemukan bahwa resiliensi seseorang dipengaruhi oleh hubungan dan dukungan efektif yang berasal dari komunitas serta keluarga (Kessel, 2013, Janssen, Van Regenmortel, \& Abma, 2011). Hasil penelitian Ekedahl \& Wengström (2006) menunjukkan bahwa dukungan sosial utama bagi perawat berasal dari teman dan keluarga.

Hasil penelitiannya, Wang et al., menunjukkan hasil yang sedikit berbeda, perawat memperoleh 
dukungan sosial cukup, dan sumber dukungan sosial terbanyak berasal dari teman dibandingkan dari keluarga maupun teman sejawat. Penelitian Zander et al (2013) menunjukkan bahwa dukungan dari teman sejawat sangat penting bagi perawat onkologi. kebutuhan mencari dukungan sosial keluarga dan teman pada perawat onkologi menurun, karena mereka mendapatkan dukungan dari anggota tim kerja, bahkan pada saat suasana informal (Zander et al., 2010).

Penelitian ini bertujuan untuk mengetahui hubungan dukungan sosial terhadap resiliensi perawat pelaksana.

\section{METODE PENELITIAN Metode}

Metode penelitian ini adalah kuantitatif dengan pendekatan cross sectional.

\section{Populasi dan Sampel}

Populasi dari penelitian ini adalah seluruh perawat pelaksana yang berjumlah 129 pada sebuah rumah sakit yang berada di Padang Panjang, Sumatera Barat. Sampel diambil dengan cara proportional random sampling. Jumlah sampel dalam penelitian ini adalah 110 perawat pelaksana dengan latar pendidikan minimal DIII Keperawatan.

\section{Pengumpulan Data}

Sebelum dilakukan penyebaran kuesioner, peneliti menjelaskan mengenai tujuan penelitian, manfaat dan proses penelitian kepada perawat. Selanjutnya peneliti menjelaskan pilihan untuk berpartisipasi atau tidak. Responden tidak dipaksa untuk ikut serta dalam penelitian dan diberi kebebasan untuk memilih berpartisipasi atau tidak. Responden mengisi form informed consent sebagai bukti persetujuan bersedia berpartisipasi dalam penelitian atau tidak. Data dikumpulkan selama satu bulan dengan cara menyebarkan kuesioner secara langsung kepada perawat pelaksana.

Penelitian ini telah lolos kaji uji etik telah peneliti dapatkan dari komite etika penelitian Fakultas Kedokteran Universitas Andalas ditandai dengan didapatkannya surat keterangan lolos uji etik nomor 089/KEP/FK/2019

\section{Instrument Penelitian}

Peneliti menggunakan instrument 10-item Connor Davidson Resilience Scale (10 item CD RISC) yang dikembangkan oleh Sills \& Stein (2008). CD-RISC dilindungi hak cipta dan izin sudah diperoleh peneliti.
Instrumen ini terdiri dari 10 pertanyaan. Pilihan jawaban terdiri dari skor 0 "Tidak Setuju" sampai dengan skor 4 untuk "Sangat Setuju". Rentang skor 10-item CD RISC yaitu 0-40.

Instrumen CD-RISC10 telah dipakai pada berbagai populasi termasuk pada perawat (Ang, 2018) dan memiliki validitas konstruk yang baik (Sills and Stein, 2008). Pada penelitian Ang (2018) pada perawat di Singapura, 10 item CD RISC menunjukkan reliabilitas konsistensi internal adalah 0,91 (Cronbach's alpha).

Hasil uji validitas mengenai CD-RISC10 didapatkan nilai $r$ hitung 10 item pertanyaan adalah antara 0,578-0,892 ( $r$ hitung $>r$ table yaitu 0.361). Selanjutnya hasil uji reliabilitas didapati nilai cronbach's alpha pada kuesioner resiliensi yaitu 0.,933 (>0,60).

Variabel dukungan sosial diukur dengan menggunakan The Multidimensial Scale Perceived Social Support (MSPSS). Instrumen ini dikembangkan oleh Zimet (1988). Instrumen ini terdiri atas 12 item pertanyaan dukungan sosial yang diterima responden. Perincian instrumen ini yaitu sebanyak empat item pertanyaan dukungan sosial dari keluarga, empat item pertanyaan dukungan sosial dari teman dan empat item pertanyaan dukungan sosial dari significant other's yang pada penelitian ini merupakan teman sejawat.

Versi asli dari skor MSPSS 12 item pertanyaan dengan rentang skala likert 1-7. Pilihan jawaban terdiri dari skor 0 "Sangat Tidak Setuju" sampai dengan skor skor 4 untuk "Sangat Setuju". Rentang skor MSPSS yaitu 0-48 (Stewart, et al, 2014). Peneliti melakukan modifikasi terhadap skor kuesioner MSPSS.

Hasil uji validitas tentang dukungan sosial didapatkan nilai $r$ hitung 12 item pertanyaan antara 0,691-0,935 ( $r$ hitung>0,361). Hasil uji reliabilitas didapati nilai cronbach's alpha pada kuesioner dukungan sosial 0,958 (>0,60). Hasil ini menunjukkan bahwa kuesioner MSPSS dengan skala likert 0-4 valid dan reliable untuk digunakan dalam penelitian.

\section{Analisis Data}

Data dianalisis dengan menggunakan tes ChiSquare, pada level signifikansi $\alpha=0.05$ untuk mengetahui hubungan antara dukungan sosial dan resiliensi perawat pelaksana.

\section{HASIL DAN PEMBAHASAN}

Hasil pada tabel 1 menunjukkan bahwa lebih dari separuh responden berada pada usia dewasa awal (2635 tahun), hampir seluruh responden berjenis kelamin perempuan (87.3\%) dan separuh responden bekerja kurang sama 10 tahun $(53,6 \%)$.

Tabel 1. Karakteristik Responden

\begin{tabular}{|c|c|c|c|}
\hline & Karakteristik & frekuensi & Persentase (\%) \\
\hline \multirow[t]{5}{*}{ Umur } & 17-25 tahun (Remaja Akhir) & 2 & 1,8 \\
\hline & 26-35 tahun (Dewasa Awal) & 63 & 57,3 \\
\hline & 36-45 tahun (Dewasa Akhir) & 41 & 37,3 \\
\hline & 46-55 tahun (Lansia Awal) & 3 & 2,7 \\
\hline & 56-65 tahun (Lansia Akhir) & 1 & 0,9 \\
\hline \multirow[t]{2}{*}{ Jenis Kelamin } & Laki-laki & 14 & 12,7 \\
\hline & Perempuan & 96 & 87,3 \\
\hline \multirow[t]{3}{*}{ Lama Kerja } & $\leq 10$ tahun & 59 & 53.6 \\
\hline & $11-20$ tahun & 42 & 38.2 \\
\hline & $\geq 20$ tahun & 9 & 8.2 \\
\hline
\end{tabular}


Tabel 2 Rerata Dimensi Dukungan Sosial

\begin{tabular}{lcc}
\hline & Dimensi & Mean \\
\hline Dukungan Keluarga & & 2,30 \\
Dukungan Teman & Dukungan Teman Sejawat & 2,07 \\
& & 2,26 \\
\hline Total & & 2,21 \\
\hline
\end{tabular}

Tabel 3. Hubungan Dukungan Sosial dengan Resiliensi Perawat

\begin{tabular}{|c|c|c|c|c|c|c|c|c|}
\hline \multirow[t]{2}{*}{ Dukungan Sosial } & \multicolumn{4}{|c|}{ Resiliensi } & \multirow[t]{2}{*}{ Total } & \multirow[t]{2}{*}{$P$ value } & \multirow[t]{2}{*}{ OR } & \multirow[t]{2}{*}{$95 \%(\mathrm{Cl})$} \\
\hline & Rendah & $(\%)$ & Tinggi & $(\%)$ & & & & \\
\hline Rendah & $\begin{array}{l}46 \\
11\end{array}$ & 83.6 & $\begin{array}{c}9 \\
44\end{array}$ & 16.4 & $\begin{array}{l}55 \\
55\end{array}$ & 0.000 & 20.444 & $7.726-54.07$ \\
\hline
\end{tabular}

Tabel 2 memperlihatkan bahwa rerata dimensi dukungan sosial yang paling tinGgi yaitu dimensi dukungan keluarga dan yang paling terendah adalah dimensi dukungan teman. Hal ini menunjukkan bahwa dukungan terbesar yang diterima perawat adalah dukungan yang berasal dari keluarga.

Hasil penelitian ini sejalan dengan penelitian Öksüz et al (2018) bahwa dukungan sosial yang terbesar yang dirasakan oleh perawat adalah berasal dari keluarga. Selain itu, pada penelitian ini, hampir seluruh responden berjenis kelain perempuan. Dukungan sosial dari keluarga terdekat seperti suami dan keluarga besar sangat diperlukan pada perempuan yang bekerja khususnya perawat perempuan. Menurut Yunita \& Kismono (2014) perempuan akan cenderung tidak dapat memenuhi perannya di rumah ketika sedang dalam tekanan di tempat kerja. Hal ini berkaitan dengan perempuan memiliki peran ganda ketika ia bekerja di luar rumah sehingga memungkinkan terjadinya konflik yang pada akhirnya dapat berefek pada pekerjaan.

Ketika seorang perempuan yang juga bekerja sebagai perawat mengambil sebuah keputusan terkait pekerjaan yang berhubungan dengan rumah tangga, seperti misalnya keperluan lembur pekerjaan ataupun karena akreditasi, hendaknya bisa didiskusikan bersama suami atau keluarga besar memberikan masukanmasukan yang berarti. Diharapkan bisa ditemukan solusi seperti penyesuaian jadwal sehingga dikemudian hari konflik di rumah tangga maupun yang nantinya berefek pada pekerjaan yang mungkin terjadi bisa diminimalisir.

Disinilah peran keluarga untuk dapat membantu bersama-sama mengambil keputusan dan berbagi peran di rumah. Menurut Yunita \& Kismono (2014) seseorang yang mendapat dukungan keluarga lebih mungkin untuk mengatur kelelahan fisik sehingga mereka bisa lebih berkonsentrasi dalam bekerja yang mencegah untuk keluar (resign) dari pekerjaan mereka.

Dimensi dukungan teman menjadi dimensi dukungan yang paling kecil dirasakan oleh perawat pada penelitian ini dapat dikarenakan karakteristik responden yang hampir seluruhnya merupakan perawat berstatus menikah dan berada di atas usia 25 tahun. Berdasarkan hasil penelitian Prezza \& Pacilli (2002) dukungan yang paling dirasakan oleh orang yang telah menikah berasal dari keluarga dan orang terdekat seperti suami. Menurut $\mathrm{Li}$, Ji, Chen (2014). Pada saat seseorang menikah maka dukungan teman untuk mengurangi emosi negatif jauh berkurang dibanding dengan dukungan dari keluarga. Begitu pula dengan usia, seiring bertambahnya usia, maka dukungan dari teman-teman akan menurun (Prezza and Pacilli, 2002).
Pada tabel 3 dapat dilihat bahwa dari 55 perawat yang mendapat dukungan sosial yang rendah, 46 perawat (83.6\%) memiiki resiliensi rendah. Tabel tersebut juga menjelaskan bahwa dari 55 orang perawat yang mendapatkan dukungan sosial tinggi, hanya 44 orang perawat yang memiliki resiliensi tinggi $(80 \%)$. Tabel 3 juga memperlihatkan terdapat hubungan antara dukungan sosial dengan resiliensi perawat $(P$ value 0.000$)$ dengan nilai OR (20.444; $\mathrm{Cl} 7.726-54.07)$. Hal Ini berarti bahwa perawat yang mendapatkan dukungan sosial yang tinggi akan cenderung memiliki resiliensi yang tinggi 20 kali dibanding dengan perawat yang mendapatkan dukungan sosial yang rendah.

Hasil penelitian ini sejalan dengan hasil hasil penelitian Hsieh \& Chang (2016) menunjukkan terdapat hubungan antara dukungan keluarga dan teman terhadap perawat yang bekerja di UGD rumah sakit jiwa di Taiwan. Ekedahl \& Wengström (2006) mengidentifikasikan bahwa dukungan sosial utama bagi perawat onkologi di sebuah rumah sakit di Swedia. Sementara itu, penelitian McDermid et al (2016) menunjukkan bahwa dukungan sosial utama untuk membangun resiliensi perawat akademik namun memiliki pengalaman di klinik adalah dukungan yang berasal dari teman sejawat.

Menurut Tusaie \& Dyer (2004) dukungan sosial merupakan faktor yang paling penting dalam resiliensi seseorang dan pemeliharaan hubungan merupakan hal yang penting dalam dukungan sosial. Sejalan dengan pendapat Hart (2012) bahwa faktor utama yang berkontribusi terhadap resiliensi perawat yaitu aspek interaksi dan koneksi.

Lebih lanjut, dukungan sosial sangat penting bagi perawat yang sering terpapar dengan situasi stress serta menghadapi kesulitan dalam pekerjaan (Kirpal, 2004, Zander, Hutton, \& King, 2010). Menurut Lee, Suchday, \& Wylie-Rosett (2012), seseorang dengan dukungan sosial lebih mampu untuk menghadapi kesulitan dibandingkan dengan orang lain yang hanya menghadapi kesulitan seorang diri. Perawat membutuhkan dukungan sosial untuk dapat menurunkan rasa stress saat menghadapi kesulitan di tempat kerja. Hal ini menunjukkan bahwa dukungan sosial diperlukan oleh perawat dalam meningkatkan resiliensi.

Perawat perlu mengidentifikasi asal dukungan sosial yang efektif bagi mereka baik itu dukungan keluarga, dukungan teman, atau dukungan teman sejawat. Menurut Li et al., (2014) dukungan keluarga yang tinggi dapat mengurangi emosi negatif. Sementara itu, dukungan sosial yang berasal dari teman biasanya biasanya tinggi pada usia muda. Hal ini dikarenakan teman membuat mereka merasa nyaman, lebih mengerti 
mereka serta menyediakan dukungan yang mereka butuhkan (Li et al., 2014, Narayanan \& Onn, 2016). Sedangkan, dukungan dari teman sejawat sangat diperlukan terutama dalam memberikan informasi pengetahuan dan bimbingan keterampilan klinis (Zander et al., 2013) serta membantu perawat di saat situasi sulit dan juga memberikan dukungan emosional (Wang et al., 2017).

\section{SIMPULAN}

Resiliensi merupakan hal yang perlu dibangun oleh perawat untuk dapat mengatasi tantangan dan kesulitan di tempat kerja serta sebagai faktor protektif mencegah stress berlebhan dan burnout. Secara teoritis, sebagai faktor lingkungan yang bersumber dari luar individu (external factor) berpengaruh terhadap resiliensi seseorang. Penelitian ini menunjukkan terdapat hubungan antara dukungan sosial dengan resiliensi perawat. Dukungan sosial terbanyak diterima perawat berasal dari dukungan keluarga dibandingkan dengan dukungan teman dan dukungan teman sejawat.

Manajemen rumah sakit dapat merancang program inovatif dan kreatif untuk meningkatkan dukungan sosial yang diterima perawat yaitu dengan program family gathering, program family hospital tour serta mentoring. Program family gathering dan hospital tour dapat dilakukan satu kali dalam setahun serta dievaluasi pada setiap akhir pogram. Program ini dapat dilaksanakan saat moment tertentu seperti ulang tahun atau hari jadi rumah sakit. Sementara itu, dana bisa diperoleh melalui kerjasama rumah sakit dengan sponsor.

Pada program family gathering dan hospital tour, yang dilakukan di luar lingkungan rumah sakit dan mengajak serta keluarga perawat diharapkan meningkatkan bonding dan dukungan keluarga terhadap anggota keluarganya yang bekerja sebagai perawat. Sementara program mentorship dinilai dapat semakin mempererat sesama perawat pelaksana secara emosional. Melalui program ini diharapkan dukungan sosial meningkat dan berpengaruh pula terhadap peningkatan resiliensi.

\section{DAFTAR PUSTAKA}

Ablett, J. R. and Jones, R. S. P. (2006) 'Resilience and well-being in palliative care staff: A qualitative study of hospice nurses ' experience of work', Psycho-Oncology, 740(December 2006), pp. 733740. doi: $10.1002 /$ pon.1130.

Ang, et al (2018) 'Association between Demographics and Resilience - a Cross-Sectional Study among Nurses in Singapore', International Nursing Review, pp. 1-8. doi: 10.1111/inr.12441.

Cam, O. and Buyukbayram, A. (2015) 'The Results of Nurses' Increasing Emotional Intelligence and Resilience', Journal of Psychiatric Nursing, pp. 130-136. doi: 10.5505/phd.2015.96729.

Cameron, F. and Brownie, S. (2010) 'Enhancing Resilience in Registered Aged Care Nurses', Australasian Journal on Ageing. doi: 10.1111/j.1741-6612.2009.00416.x.

Ekedahl, M. and Wengström, Y. (2006) 'Nurses in cancer care-Stress when encountering existential issues', European Journal of Oncology Nursing,
11(3), pp. 228-237. doi:

10.1016/j.ejon.2006.09.005

Gillespie, B. M., Chaboyer, W. and Wallis, M. (2009) 'The influence of personal characteristics on the resilience of operating room nurses: A predictor study', International Journal of Nursing Studies, 46, pp. 968-976. doi: 10.1016/j.ijnurstu.2007.08.006.

Hart, P. L. (2012) 'Resilience in nurses: an integrative review', Journal of Nursing Management, (Oulton 2006). doi: 10.1111/j.1365-2834.2012.01485.x.

Hsieh, H. and Chang, S. (2016) 'The relationships among personality, social support, and resilience of abused nurses at emergency rooms and psychiatric wards in Taiwan', 0242(March). doi: 10.1080/03630242.2016.1150385.

Jackson, D., Firtko, A. and Edenborough, M. (2007) 'Personal Resilience as a Strategy for Surviving and Thriving in the Face of Workplace Adversity: a Literature review', Journal of Advanced Nursing, pp. 1-9. doi: 10.1111/j.1365-2648.2007.04412.x.

Janssen, B. M., Van Regenmortel, T. and Abma, T. A. (2011) 'Identifying sources of strength: Resilience from the perspective of older people receiving long-term community care', European Journal of Ageing, 8(3), pp. 145-156. doi: 10.1007/s10433011-0190-8.

Jooyoung, J. (2012) The Effect of Social Support Type on Resilience. Tuscaloosa, Alabama

Kessel, van G. (2013) 'The ability of older people to overcome adversity: A review of the resilience concept', Geriatric Nursing. Elsevier Ltd, 34(2), pp. 122-127. doi: 10.1016/j.gerinurse.2012.12.011

Kirpal, S. (2004) 'Work identities of nurse between caring and efficiency demands'. doi: http://dx.doi.org/10.1108/MRR-09-2015-0216.

Lee, Y. S. C., Suchday, S. and Wylie-Rosett, J. (2012) 'Perceived Social Support, Coping Styles, and Chinese Immigrants' Cardiovascular Responses to Stress', International Journal of Behavioral Medicine, 19(2), pp. 174-185. doi: 10.1007/s12529-011-9156-7.

Li, H., Ji, Y. and Chen, T. (2014) 'The roles of different sources of social support on emotional well-being among Chinese elderly', PLoS ONE, 9(3), pp. 18. doi: 10.1371/journal.pone.0090051.

McAllister M, L. J. (2011) 'Preparing for Practice: Becoming Resilient', in The Resilient Nurse: Empowering Your Practice. New York: Springer Publishing Company, pp. 1-22.

Mccann, C. M. et al (2013) 'Resilience in the health professions: A review of recent literature', International Journal of Wellbeing, 3, pp. 60-81. doi: 10.5502/ijw.v3i1.4

McDermid, F. et al. (2016) 'Developing resilience: Stories from novice nurse academics', Nurse Education Today. Elsevier B.V., 38, pp. 29-35. doi: 10.1016/j.nedt.2016.01.002.

Nantsupawat, A. and et al (2016) 'Nurse Burnout, NurseReported Quality of Care, and Patient Outcomes in Thai Hospitals', Journal of Nursing Scholarship, 48(1), pp. 83-90. doi: 10.1111/jnu.12187.

Narayanan, S. S. and Onn, A. C. W. (2016) 'The 424 
Influence of Perceived Social Support and Self Efficacy on Resilience among First Year Malaysian Student', Kajian Malaysia, 34(2), pp. 123.

Öksüz, E. et al (2018) 'Resilience in nurses in terms of perceived social support, job satisfaction and certain variables', Jurnal Nursing Management, (June), pp. 1-10. doi: 10.1111/jonm.12703.

Poghosyan, L. et al. (2010) 'Nurse burnout and quality of care: cross-national investigation in six countries.', Research in nursing \& health, 33(4), pp. 288-298. doi: 10.1002/nur.20383.

Prezza, M. and Pacilli, M. G. (2002) 'Perceived Social Support from Significant Others, Family and Friends and Several Socio-demographic Characteristics', Journal of Community and Applied Social Psychology, 429, pp. 422-429.

Ren, Y. et al (2018) 'Exploratory Study on Resilience and Its in fluencing Factors among Hospital Nurses in Guangzhou , China', International Journal of Nursing Sciences. Elsevier Taiwan LLC, 5, pp. 57-62. doi: 10.1016/j.jijnss.2017.11.001.

Rogers, A. E. et al. (2004) 'The Working Hours of Hospital Staff Nurses and Patient Safety', Health Affairs, 23(4), pp. 202-212. doi: 10.1377/hlthaff.23.4.202.

Rutter, M. (2008) 'Developing Concepts in Developmental Psychopathology', in Developmental Psychopathology and Wellness: Genetic and Environmental Influences. Washington DC: American Psychiatric Publishing, pp. 3-22.

Sarason, B. and Duck, S. (2001) Personal Relationship: Implications for Clinical and Community Psychology. Cichester, England: John Wiley \& Sons Ltd.

Sills, L. C. and Stein, M. B. (2008) 'Psychometric Analysis and Refinement of the Connor-Davidson Resilience Scale (CD-RISC): Validation of a 10Item Measure of Resilience', Journal of traumatic stress, 21(1), pp. 75-82. doi: 10.1002/jts.

Sippel, L. M. et al. (2015) 'How does social support enhance resilience in the trauma-exposed individual?', Ecology and Society, 20(4). doi: 10.5751/ES-07832-200410.

Stewart, R. C. et al. (2014) 'Validation of the multidimensional scale of perceived social support ( MSPSS ) and the relationship between social support, intimate partner violence and antenatal depression in Malawi', BMC Psychiatri, pp. 1-11. Available at: http://www.biomedcentral.com/1471244X/14/180 Page.

Tusaie, K. and Dyer, J. (2004) 'Resilience: A Historical Review', Holistic Nursing Practice, 18(1)(March), pp. 3-8.

Wang, Lin, et al (2017) 'Influence of Social Support and Self-Efficacy on Resilience of Early Career Registered Nurses', Westren of Nursing Research. doi: 10.1177/0193945916685712.

$\mathrm{Xu}, \mathrm{Y}$. and Burleson, B. R. (2001) 'Effects of sex, culture, and support type on perceptions of spousal social support: An assessment of the "support gap" hypothesis in early marriage', Human
Communication Research, 27(4), pp. 535-566. doi: 10.1093/hcr/27.4.535.

Yilmaz, E. B. (2017) 'Resilience as a strategy for struggling against challenges related to the nursing profession'. doi: 10.1016/j.cnre.2017.03.004

Yunita, P. I. and Kismono, G. (2014) 'Influence of WorkFamily Conflict and Family Work Conflict on Employees Turnover Intentions With Gender, Social Support and Individual Value Moderating Effects', Journal of Indonesian Economy and Business, 29(1), pp. 17-30.

Zander, M. et al (2013) 'Exploring resilience in paediatric oncology nursing staff', Collegian. Royal College of Nursing Australia, 20(1), pp. 17-25. doi: 10.1016/j.colegn.2012.02.002.

Zander, M., Hutton, A. and King, L. (2010) 'Coping and resilience factors in pediatric oncology nurses', Journal of Pediatric Oncology Nursing, 27(2), pp. 94-108. doi: 10.1177/1043454209350154.

Zimet, et al (1988) 'The Multidimensional Scale of Perceived Social Support', Journal of Personality, 52 (1), pp. 30-41. 